\title{
Computer-supported environmental management - why simulation methods are useful
}

\author{
L. M. Hilty \\ Department of Informatics, University of Hamburg \\ Vogt-Koelln-Str. 30, 22527 Hamburg, Germany \\ Tel: ++49/40/54715-309, Fax: -311, hilty@informatik.uni-hamburg.de
}

\begin{abstract}
Two approaches to use computer simulation methods for ecological assessment are presented: The "Material Flow Network" approach based on the well-known formalism of Petri Nets and the "Eco-Logistics" approach based on the integration of simulation and geographic information systems. These two approaches allow investigation of the dynamic behavior of complex systems in the conflict between economy and ecology. They can therefore serve as a central part of decision support systems for environmental management, supporting the simulation of "what if"-scenarios and aiding the user in finding a strategy with high ecological efficiency.
\end{abstract}

Keywords

Environmental Management System, Life Cycle Analysis, Simulation Modeling

\section{BACKGROUND AND TERMINOLOGY}

Environmental management needs to be supported by computer-aided environmental information and management (CAEM) systems. Although comprehensive software systems for this purpose are not yet available, there are some programs that support the basic task in environmental management: environmental assessment.

However, the methods and software tools for environmental assessment developed so far are backward-oriented, static, and do not account for causal mechanisms in the complex economical and ecological systems under study.

The need for environmental management systems in industrial production is a recent challenge to information technology, and has stimulated a broad range of activities in Applied Computer Science particulary in Europe (Hilty, 1994a, 1995). An environmental management system is the overall framework for the actions that an enterprise takes to manage its effects on the environment (Little, 1993). Regulations such as the Environmental Management Standard BS7750 (British Standard Institution, 1992) and the EC "Eco-Management and Audit Scheme" (Commission of the EC, 1993) are intended to standardize this framework. Information systems 
designed to support such actions or the overall framework are sometimes called Environmental Management Information Systems (EMIS), Industrial Environmental Information Systems or Computer-aided Environmental information and Management (CAEM) systems (Hilty, 1995), depending on the context in which the respective systems were designed. The terminology in this new field is far from being consistent.

One specific approach to such systems is to extend existing production planning and control (PPC) systems in such a way as to help to reduce emissions into air, water or soil. Systems emerging from this approach are also known as Environmentally-oriented PPC (EPPC) systems (Haasis, 1992). Considerable emission reductions arle possible when such systems are implemented in industrial production plants. Moreover, the idea of integrating information systems for production and recycling leads to Production and Recycling Planning and Control (PRPC) systems (Rautenstrauch, 1994).

Other specific approaches emerge from the field of so-called "ecobalances". This term refers to studies or methods that are used to investigate the mass and energy flows in a given system, assess their ecological impacts, and (e)valuate them in the framework of ecological valuation criteria. There are at least two different ideas behind the term "ecobalance":

1. The ecological effects of any system can be described on the physical level in terms of mass and energy flow through (and transformation caused by) the system. Therefore, the physical inputs and outputs of the system can be put on the two sides of a balance sheet (see figure 1). According to the first law of thermodynamics, input and output must be balanced if measured in physical units. The transformation caused by the system can be described as an increase of entropy, according to the second law of thermodynamics (entropy law).

2. Environmental assessment is regarded as an extension of traditional business accounting, assuming that environmental effects should be recorded and analysed with the same systematics and accuracy as monetary transactions are. This idea traces back to the Swiss engineer Müller-Wenk, who invented a system of ecological accounting based on a non-monetary (and non-physical) measuring unit for environmental effects, expressing the ecological scarcity of limited resources, including limited capacities of regeneration processes.

In Europe, a broad range of methods for ecological assessment are subsumed under the notion of ecobalance today. An important group is formed by ecobalances for products, better known as Life Cycle Assessments (LCA). The goal is to assess the environmental impacts of a product "from cradle to grave", i.e., from the extraction of raw materials up to waste disposal. There is a variety of LCA methods (Weidema, 1993).

A second group of ecobalances considers one company or one plant of a company. It can be viewed as a special case of the earlier concept of "social accounting", which aimed to account for social impacts of a company's activities in general ("put people on your balance sheet"). This approach may have failed because of its comprehensive demand. However, putting the environmental impacts of a company onto a balance sheet seems to be the easier (because more specific) task, although it is complex enough and may not even be characterized as a well-defined problem.

One of the first approaches to ecobalances for companies was Müller-Wenk's "ecological accounting" developed in the seventies. It is based on the concept of ecological scarcity, which allows for the quantification of all types of environmental impacts on a single scale. This approach was later developed into the method of eco-balances recommended by the Swiss Federal Office of Environment, Forestry and Landscape. 


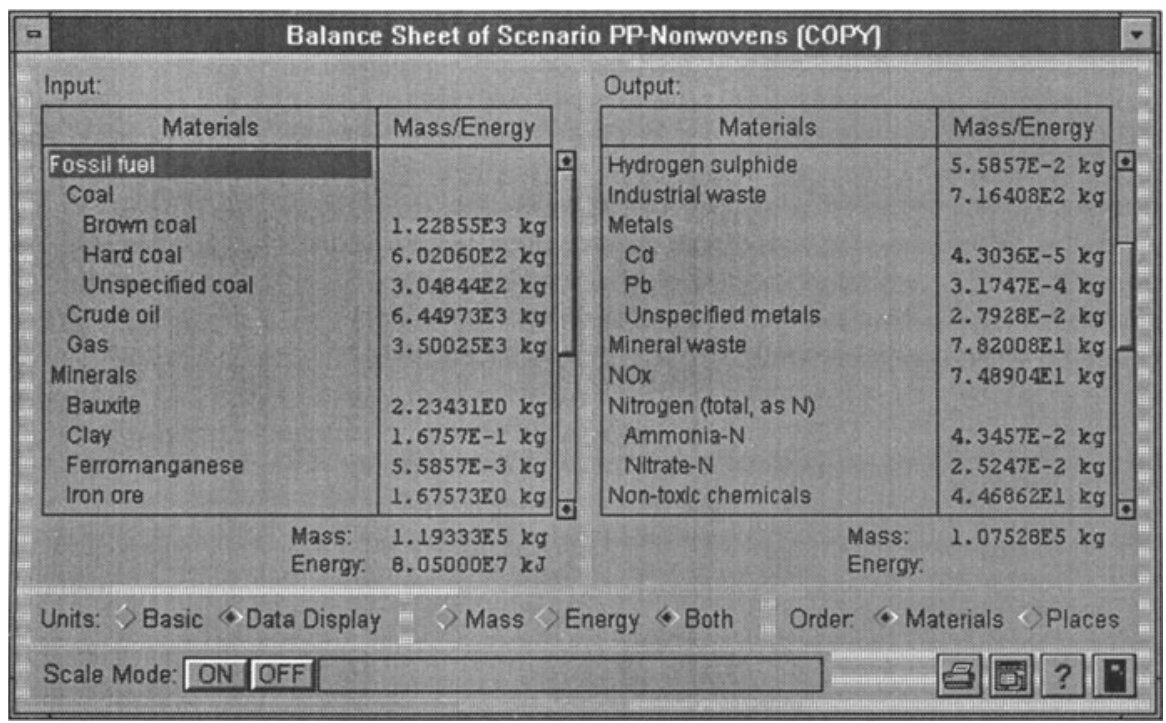

Figure 1 Small section of an ecological balance sheet for polypropylene (PP) production. Mass input and output are approximately balanced, whereas energy is not. (The reason for the latter is that waste heat was not measured for this study.) This figure is a screen copy from the Umberto software.

\section{MOTIVATION FOR ENVIRONMENTAL MANAGEMENT}

Environmental assessments of companies, products, or production processes are the starting point of environmental management. The result of an environmental assessment is a detailed documentation of environmental effects. These are changes to the environment caused by an activity. They can be divided into resource consumption (raw material and energy consumption), emissions or discharges (gaseous, airborne, liquid, dissolved or solid waste), and welfare effects on humans and possibly other organisms (including health effects).

Based on the information gained in a basic environmental assessment, a company can check legal compliance, identify the most significant environmental effects, and define an environmental policy. Further steps to environmental management are the initiation of more detailed environmental assessments of selected aspects, the arrangement of independent environmental audits, and finally the introduction of an environmental management system (Little, 1993, see figure 2). 


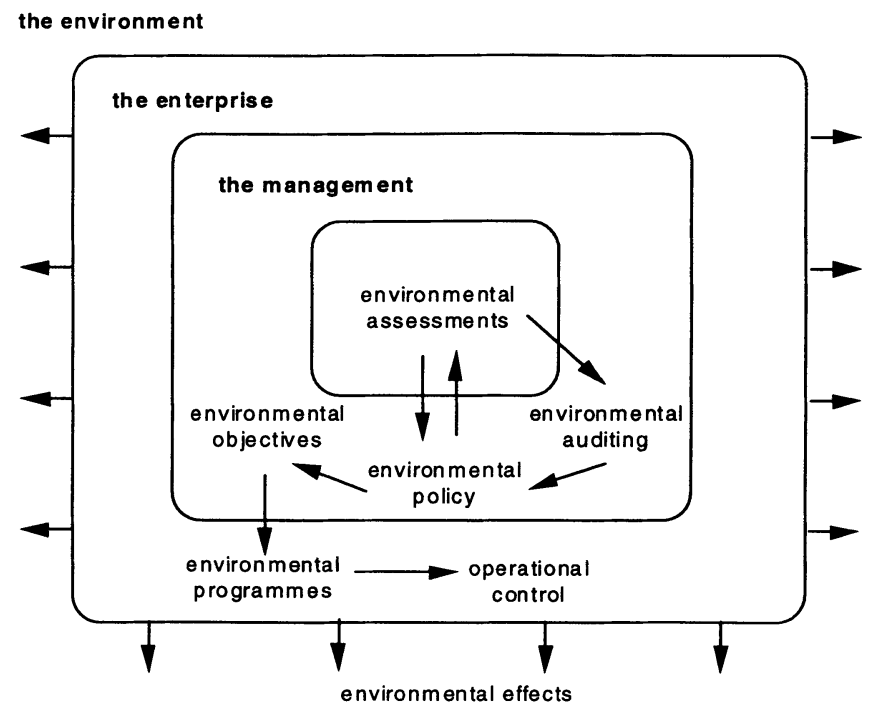

Figure 2 Elements of an environmental management system (following Little, 1993).

The main motivation for environmental management is the external demand for environmentrelated information about the enterprise and its products:

- Consumers increasingly consider ecological criteria when choosing a product or a service. This results in a demand for product- and company-related environmental information.

- Suppliers and buyers, in expectation of a long-term business relationship, need environmental information of their partner in order to minimize the risk of getting involved in environmental problems and scandals.

- Investors (shareholders and creditors) often consider ecological aspects. Banks, for instance, take the potential contamination of a site into consideration when granting a mortgage. Environmentally oriented investors choose the least ecologically damaging company if the capital return is otherwise equal.

- The insurances industry has to identify and evaluate the increasing liability risks resulting from environmental hazards.

\section{SOFTWARE SUPPORT FOR ENVIRONMENTAL ASSESSMENT}

To classify computer programs for environmental assessment, we differentiate between the following three levels of an environmental assessment, also known as the three steps of "ecobalancing": 
- inventory assessment: quantification of all (relevant) mass and energy flows caused by the system under study, including energy and raw material input and the related output in solid, liquid, or gaseous form; description and quantification of other forms of interaction with the environment (e.g. land utilization).

- environmental impact assessment: description and quantification of the environmental effects caused by the interactions determined in the invertory phase.

- evaluation: evaluation and presentation of the results of the preceeding phases to make them suitable for decision support. In this phase, priorities or weights are given to parameters of environmental effects, and different kinds of impacts are aggregated. Because this involves values concerning the relative importance of the parameters (e.g., health effects versus energy consumption), this phase is also called the valuation phase.

In some publications, another phase preceding the inventory assessment (goal definition, scoping/screening) is included (Fava, 1993; Umweltbundesamt, 1992). It comprises, among other issues, the definition of the system boundary, the choice of methods for the succeeding phases, and defining a strategy for data collection. At present, there seems to be no systematic approach to this first phase of environmental assessment nor, consequently, appropriate software support. ${ }^{1}$

The available software systems usually focus on one of the three steps listed above. They can therefore be classified into inventory-, impact- and (e)valuation-oriented systems. Most systems mentioned here are described in more detail either in the textbook "Product Life Cycle Assessment" (Weidema, 1993) or in the proceedings of the conference "Informatics for Environmental Protection" (Hilty, 1994a), volume II.

\subsection{Inventory-oriented Systems}

The most basic step of ecological assessment is collecting reliable data and integrating it into a model of mass and energy flow which is a consistent and valid representation of the system under study.

One of the first software systems developed in this field was the LCA inventory tool (Chalmers Industrieteknik, Sweden), which supports modeling product life cycles with directed graphs. A database with the emission data of the most important production, transport and energy generation processes is provided.

The Umberto system (Institute for Environmental Informatics, Hamburg, in cooperation with the Institute for Energy and Environmental Research, Heidelberg, Germany) supports the modeling of mass and energy flow systems based on so-called material flow nets, an interpretation of Petri Nets. Ecobalances of companies, products, production and disposal processes on different system levels can be treated the same way. An expandable library with predefined modules for energy production, raw material production, transport and waste disposal is available (Umberto is discussed in more detail in section 4).

Further inventory-oriented systems are TEA (Tools for Ecological Analysis, Ecobilan, France), IDEA (International Database for Ecoprofile Analysis, Technical Centre of Finland), and TEMIS (Total Emission Model for Integrated Systems, Öko-Institut Darmstadt, Germany).

1 This may change in future when the ISO 14000 series is established. 


\subsection{Impact-oriented Systems}

For an estimate of ecological impacts, chemical substance data and their behaviour in the environment are needed.

The program SimaPro2 (Pré, The Netherlands) was conceived to support ecological product development. With the use of a database for materials and production processes, the direct and indirect environmental effects of a proposed product variant can be assessed.

Furthermore, there are several on-line chemical databases offered worldwide which document the environmental effects of chemical substances, e.g., the IRPTC (International Register of Potentially Toxic Chemicals, Health and Welfare, Canada).

\section{3 (E)valuation-oriented Systems}

The program EPS (Environmental Priority Strategies, Swedish Environmental Research Institute) supports the evaluation of resource consumption and emissions by quantifying the environmental burdens in monetary units. Other valuation concepts (like ecological scarcity) can be considered as well.

EXCEPT (IBM Germany, in cooperation with the Technical University of Hamburg) is a knowledge-based system which supports complex, rule-based ecological valuation methods. Here, the most important aspect is the documentation and explanation of valuation methods and the comparison of alternative assessments (Weiland, 1993).

\section{MODELING SYSTEMS OF MASS AND ENERGY FLOW WITH PETRI NETS}

Practical experience gained in large ecobalance projects lead to the development of the software tool Umberto (Schmidt, 1994. This tool is designed and implemented on the basis of Petri Net theory. Petri Nets have already proven to be useful in modeling systems of information flow; they are exploited in Umberto to support comprehensive and consistent modeling of mass and energy flow systems such as production systems or product life cycles.

Usually, life-cycle assessments are calculated by means of an extended matrix calculation, which causes the method to appear less transparent and more difficult to handle than it should be. These problems are overcome by means of the Petri Net approach. This formalism is suited for modeling systems in which flows of information, matter or energy play a central role. The systems are represented by graphs with two sorts of nodes which must strictly alternate: socalled transitions, representing transformation processes, and places, which represent, for instance, depots.

Net theory was combined with concepts of ecological accounting by Möller (1994) and led to a new type (or interpretation) of the Petri Net formalism: material flow networks. The pilot application of this approach and the Umberto software was an international LCA project in which data from more than 90 European companies were collected, structured and integrated into an LCA tree for disposable diapers. Figure 3 shows a small portion of the whole network, which would cover more than one square meter if printed on paper in the same size and aggregation level. 


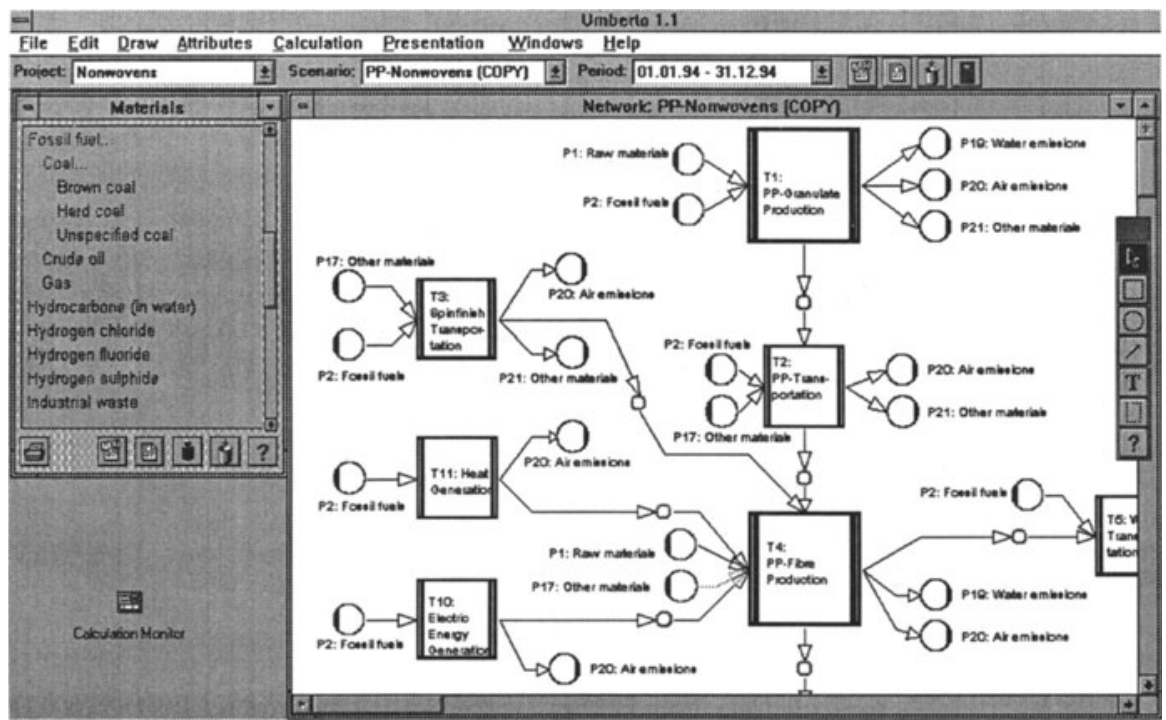

Figure 3 Small section of the network representirng the product life cycle of polypropylene (PP) nonwovens from raw materials to waste treatment. The window entitled 'Materials' shows a part of the project-specific materials classification. This figure is a screen copy from the Umberto software.

The following table shows how real systems are mapped to the Petri Net formalism and its graphical representation.

\begin{tabular}{|l|l|l|l|}
\hline real system & $\begin{array}{l}\text { Petri Net } \\
\text { (conceptual model) }\end{array}$ & $\begin{array}{l}\text { graphical } \\
\text { representation }\end{array}$ & comment \\
\hline $\begin{array}{l}\text { process } \\
\text { (production, transport, } \\
\text { consumption/use, waste } \\
\text { treatment) }\end{array}$ & $\begin{array}{l}\text { transition } \\
\text { (specified by an arbitrary } \\
\text { mathematical function } \\
\text { definition) }\end{array}$ & rectangle & $\begin{array}{l}\text { The function defines the } \\
\text { input/output relation. }\end{array}$ \\
\hline $\begin{array}{l}\text { storage } \\
\text { (any place where material } \\
\text { is located before or after } \\
\text { being processed) }\end{array}$ & place & circle & $\begin{array}{l}\text { One place can } \\
\text { accommodate different } \\
\text { materials. }\end{array}$ \\
\hline $\begin{array}{l}\text { material flow } \\
\text { (flow from a place into a } \\
\text { process or from a process } \\
\text { to a place) }\end{array}$ & arc & arrow & $\begin{array}{l}\text { Different materials can } \\
\text { flow "through" one arc. }\end{array}$ \\
\hline
\end{tabular}

Different parts of the network can subsequently be combined to form a new transition. This makes it possible to build up hierarchical network structures. Moreover, it is possible to extract an input/output balance for the environmentally relevant parameters at any point of the network. 
The Petri Net approach has considerable advantages for complex LCA projects. Mainly,

- it helps to model systems of mass and energy flow in a flexible and mathematically consistent manner;

- it supports interactive graphical modeling in both top-down and bottom-up directions (stepwise refinement of models and modeling by combining basic building blocks, respectively);

- it allows the use of a "spreading activation" approach to network calculation, so that a partial numerical evaluation of a network model or any model fragment can take place at any time; inconsistencies detected due to data redundancy are fed back to the user immediately;

- it allows an algorithm of truth maintenance to be used, so that recalculation of inferred values - after the user has altered a value - is performed only if necessary.

\subsection{Petri Nets and simulation}

If an industrial production system or product life cycle is once modelled in the form of a Petri Net, it is possible to simulate its dynamic behaviour. For decision support in environmental management, especially the following applications of simulation seem promising:

- comparing the environmental effects of planned product or process alternatives,

- assessing the consequences of introducing new materials into a product life cycle or production systems, especially under the aspect of waste treatment,

- planning and controlling integrated recycling and production processes under uncertain assumptions about return rates and quality of used products.

\section{ECO-LOGISTICS AND THE "MOBILE" PROJECT}

The second approach to apply simulation methods in environmental management to be discussed here requires again some preliminary remarks on terminology.

The concept of logistics, which originates from the military context, has been generalized to methods for coodinating people and/or goods in space and time in order to maximize the benefits and to minimize the cost. In economic terms, production factors (people, machines, material...) have to be combined for the purpose of production, and people and goods must come together for the purpose of consumption. The aim of logistics is an optimal design and control of systems of physical or information flow.

This general concept can further be extended to eco-logistics (Hilty, 1994c) by considering ecological scarcity of resources and environmental pollution in addition to monetary costs. This is important because the ecological impacts of the traffic sector are not adequatly indicated by the monetary cost of transportation.

Some simulation models have been developed for specific problems in this field, e.g. for the environmental impacts of "just in time" delivery and production strategies (Hilty, 1994b) and for commuter traffic in crowded areas (Hilty, 1994d).

The research project "Mobile" ("Model base for an integrative view of logistics and environment") at the University of Hamburg has the objective to develop an object-oriented model base system for eco-logistics. The model base is a growing collection of simulation model components that can be easily combined into problem-specific models for a broad range of applications. 


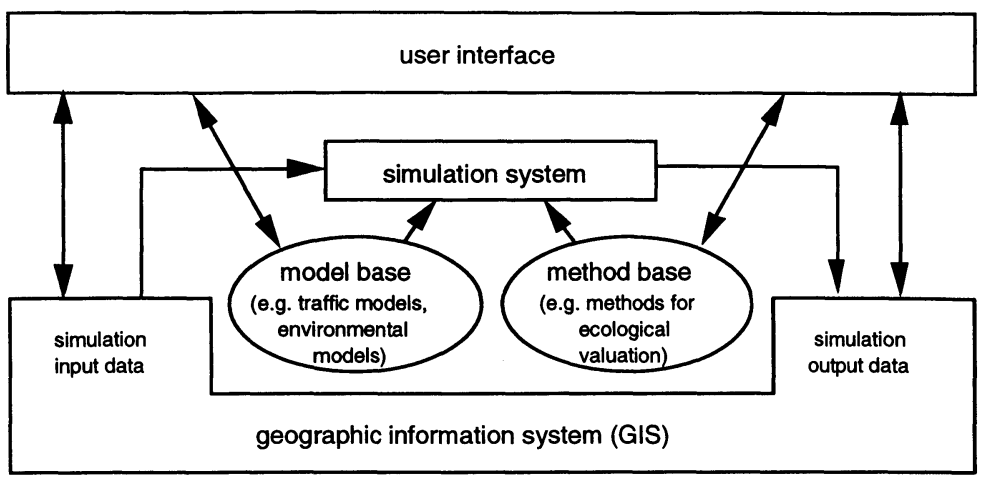

Figure 4 Architecture of the model base system developed in the Mobile project. This interdisciplinary project is supported by the Deutsche Volkswagen-Stiftung.

This approach differs from the Petri Net approach discussed in section 5 in the following respects:

- All processes can be located in geographic space, whereas Petri Nets have no such concept of space.

- Processes can be attributed to actors, and actors can change their location according to individual strategies.

- The combination of discrete-event and continuous model components is possible, which is necessary, e.g., when micro- and macroscopic traffic models are to be integrated or when discrete event emission models and continuous atmospheric dispersion models are coupled.

\section{CONCLUSION AND OUTLOOK}

There is a variety of approaches to support environmental assessments by sophisticated software systems, emerging from the field of "ecobalances". These approaches usually rely on static models of the system under investigation. However, it is necessary for environmental managment to consider the dynamic behaviour of systems, e.g. the interactions of production, consumption and recycling processes. This requires the use of computer simulation methods for decision support in environmental management.

Two approaches already try to meet this requirement. The material flow network approach implemented in the Umberto Software and the modelling and simulation approach to ecologistics developed in the Mobile project.

However, the environmental assessment of past or future decisions is only the basic part of environmental management. In the long run, integral Computer Aided Environmental Management (CAEM) systems will have to be developed. The overall framework for integral CAEM systems will be set by standards such as the ISO 14000 standards family, which is expected to play a similar role for environmental managment as the ISO 9000 series did for quality management. 


\section{REFERENCES}

British Standard Institution (1992) Specification for Environmental Management Systems. BS 7750. BSI, London.

Commission of the European Communities: Council Regulation (EEC) No. 1836/93 of 29 June 1993 allowing participation by companies in the industrial sector in a Community ecomanagement and audit scheme. Official Journal of the EC, L168/1-18, 10 July 1993.

Fava, J.A.; Consoli, F.; Denoson, R.A. (1993) Analyses of Product Life Cycle Assessment Applications, in Weidema (1993), 15-26

Haasis, H.-D.; Rentz, O. (1992) "Umwelt-PPS" - Ein weiterer Baustein der CIM-Architektur? in Information als Produktionsfaktor (eds. W. Görke, H. Rininsland, M. Syrbe), Proceedings 22. GI-Jahrestagung Karlsruhe, Springer-Verlag, Berlin.

Hilty, L.M.; Jaeschke, A.; Page, B; Schwabl, A. (eds.) (1994a) Informatik für den Umweltschutz, 8. Symposium, Hamburg 1994. Volume II, Metropolis, Marburg.

Hilty, L.M.; Page, B.; Martinssen, D. (1994b) Designing a Simulation Tool for the Environmental Assessment of Logistical Systems and Strategies. In Computer Support for Environmental Impact Assessment (eds. G. Guariso, B. Page), IFIP Transactions B-16, NorthHolland, Amsterdam .

Hilty, L.M.; Weiland, U. (1994c) Sustainable Cities - Opportunities and Risks of Information Technology. In Proceedings of the 13th World Computer Congress (eds. K. Brunnstein, E. Raubold), Volume II, Elsevier, Amsterdam, 613-18.

Hilty, L.M. (1994d) Ökologische Bewertung von Verkehrs- und Logistiksystemen - Ökobilanzen und Computersimulation. Hochschule St.Gallen, IWÖ-Beitrag Nr. 18, St.Gallen.

Hilty, L.M. (1995) Information systems for industrial environmental management, in Environmental Informatics - Methodology and Applications of Environmental Information Processing (ed. N. Avouris), Kluwer Academic Publishers, Dordrecht.

Little, B.; Weidema, B.P. (1993) Environmental Management Systems, in Weidema (1993), 27 38.

Möller, A. (1994) Stoffstromnetze. in Hilty (1994a), Volume II, 223-30.

Rautenstrauch, C. (1994) Integrating Information Systems for Production and Recycling, in Hilty (1994a), Volume II, 183-90.

Schmidt, M.; Giegrich, J.; Hilty, L. M. (1994) Experiences with ecobalances and the development of an interactive software tool. in Hilty (1994a), Volume II, 101-08.

Umweltbundesamt (1992): Ökobilanzen für Produkte. Bedeutung - Sachstand - Perspektiven. UBA-Texte 38/92, Berlin.

Weidema, B.P. (ed.) (1993) Environmental Assessment of Products. UETP-EEE - The Finrish Association of Graduate Engineers, Helsinki.

Weiland, U.; Pietsch, J.; Hübner, M. (1993) The EXCEPT-Project: Expert System for Computer-Aided Environmental Planning Tasks, in Proc. IFIP Working conference on Computer Support for Environmental Impact Assessment (CSEIA) 1993, Como, 358-67.

\section{BIOGRAPHY}

The author was born in Switzerland, took his doctor's degree in Computer Science (Informatics) at the University of Hamburg and worked in various research projects in the field of environmental information processing. At present, he is in charge of the MOBILE project. 